\title{
An Automatic Thermal Cycling based Test Platform for Thermoelectric Generator Testing
}

\author{
Júlio Cezar de Cerqueira Véras \\ Coordination Section of Electronics \\ Federal Institute of Pernambuco - IFPE \\ Campus de Garanhuns \\ Garanhuns, Brazil \\ julio.veras@garanhuns.ifpe.edu.br
}

\author{
Bruno Willian de Souza Arruda \\ Post-Graduate Program in Electrical Engineering - PPgEE - COPELE \\ Department of Electrical Engineering \\ Federal University of Campina Grande - UFCG \\ Campina Grande, Paraíba, Brazil \\ bruno.arruda@ee.ufcg.edu.br
}

\author{
Débora Alburquerque Vieira, Ewerton C. S. Melo and Cleonilson Protásio de Souza \\ Department of Electrical Engineering \\ Federal University of Paraíba - UFPB \\ João Pessoa, Paraíba, Brazil \\ \{debora.vieira, emelo, protasio\}@cear.ufpb.br
}

\begin{abstract}
Thermoelectric (TE) modules are solid-state devices that convert directly thermal energy in electrical energy. However, they can undergo performance degradation due to thermal cycling. In the present study, a control-based test platform that is capable to apply specific thermal cycling pattern at periodic intervals is presented in order to evaluate performance degradation that influence the TE module lifetime. Using this test platform, some parameters and the figure of merit $\mathrm{ZT}$ of a commercial TE module are measured before and after thermal cycling application. An important feature of the proposed platform is that the applied thermal cycling is bipolar, that is, it is possible to apply positive or negative temperature difference and, through this, performance degradation would be observed after only 548 thermal cycles much lower than previous works.

Index Terms-Thermal cycling; experimental platform; performance degradation evaluation.
\end{abstract}

\section{INTRODUCTION}

Thermoelectric (TE) modules are solid-state devices used in the direct conversion between thermal energy and electrical energy [1][2][3][4][5]. A TE module can either operate in an electrical power generation configuration, which a temperature gradient generates a electrical potential difference that, in this case, the TE module can be denominated Thermoelectric Generator (TEG), or in a thermal power generation configuration, which an electrical energy generates a temperature gradient that, in this case, the TE module can be denominated Thermoelectric Cooler (TEC). The higher is the temperature gradient $\Delta T=T_{H}-T_{C}$ on the hot and cold sides of the TEG (see Figure 1), the higher is the resulted electric voltage $V_{S}$, where this relation is given by the $V_{S}=\alpha \Delta T$, where $\alpha$ is the Seebeck coefficient. Taking TEC into consideration, the higher is the electrical current $I$ applied into this, the higher is temperature gradient $\Delta T$ produced by the heat flow produced, $Q_{p}$, where this relation is given by the $Q_{p}=\pi I$, where $\pi$ is the Peltier coefficient.

Thermoelectric conversion efficiency is limited accordingly to the intrinsic materials [6][7][8] that the TE modules are composed of. However, that material can suffer degradation as a result of subjecting it to thermal stress and, consequently, thermoelectric conversion efficiency also can be degraded [6][9]. In summary, the performance of TE modules may present degradation according to the thermal cycling they are subjected [6]. In order to evaluate and to accelerate the performance degradation of TE modules, thermal cycling controlled by test platform are used.

With respect to previous test platform for thermal cycling, Park et. al [6] proposes a test platform where the temperature of only a side of the TEG-under-test is controlled and, as a result, the achieved temperature varies positively on that side, while the other side is fixed in $20^{\circ} \mathrm{C}$. In this test platform, the TEG-under-test is sandwiched between a heat spreader and water cooling block and performance degradation was observed after 2,000 thermal cycles. In other test platform, the temperature of one side of the TEG-under-test is controlled but the temperature of the other side is maintained in room temperature $\approx 23^{\circ} \mathrm{C}[1]$. Using this test platform, performance degradation was observed between 10,000 and 45,000 thermal cycles.

As can be observed in these works, only one side of the TEG is allowed to change its temperature and this does not correspond to a real situation when TEG is placed in an uncontrolled temperature environmental. In this way, a test platform that is possible to set both $T_{H}$ and $T_{C}$ in an economical and effective way is welcome and turn to be very useful to perform empirical testing on TEG.

This paper presents a test platform for TEG performance degradation evaluation which is based on a scheme that the TEG-under-test is sandwiched between two TEC which both are driven by a PID-based actuator controlled by a PC. An important feature of the proposed platform is that the applied thermal cycling is bipolar, that is, it is possible to apply positive or negative temperature difference because the symmetrical scheme used, that is, while a TEG-under-test side 
is hot, the other side is cold or vice-versa (the latter is cold, the former is hot). For both side, the maximum achieved temperature is $85^{\circ} \mathrm{C}$ and the minimum was $-5^{\circ} \mathrm{C}$. Also, performance degradation in a commercial TE module has been observed after 548 thermal cycles much lower than previous works.

\section{Thermoelectric Module}

Thermoelectric (TE) modules are devices that convert temperature differences directly into electrical energy and viceversa and are made of semiconductor pairs connected electrically in series and thermally in parallel. These semiconductor pairs consist of $n$ - and p-type thermoelectric materials (typically $\mathrm{Bi}_{2} T e_{3}$-alloys for modem commercial modules) [1] and are disposed between two ceramic plates [3][10][11], as shown in Figure 1.

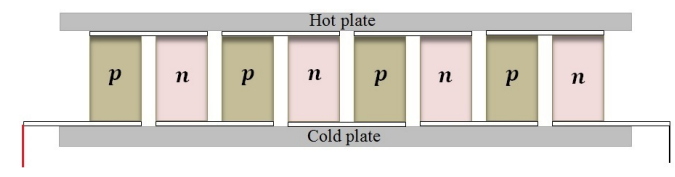

Fig. 1. Thermoelectric Module.

Basically, the operation of a TE module involves some effects, namely, Peltier, Joule, Fourier and Seebeck, that are associated with various energy transport mechanisms and phenomenon [12]. Equations (1) and (2) show the relationship between these effects, where $n$ is the number of internal p-n pairs [12].

$$
\begin{aligned}
& Q_{H}=n \alpha T_{H} I+K \Delta T-\frac{1}{2} I^{2} R \\
& Q_{C}=n \alpha T_{C} I+K \Delta T+\frac{1}{2} I^{2} R
\end{aligned}
$$

where $Q_{H}$ and $Q_{C}$ are the heat input to the TE module and heat output from the TE module, respectively, $T_{H}$ is the temperature on the hot side of the TE module, $T_{C}$ is the temperature on the cold side, $\Delta T=T_{H}-T_{C}, \alpha$ is the Seebeck coefficient, $K$ is the thermal conductance, $I$ is the current owing into the TE module, and $R$ is the TE electrical resistance.

From Equations (1) and (2), the first term, $n \alpha T_{H} I$, represents the Peltier and Seebeck effects relationship that validates the reversibility presented by the TE module. The second one, $K \Delta T$, represents the Fourier effect and express the heat conduction, and the third term, $\frac{1}{2} I^{2} R$, is the Joule heating effect. The Joule heat is distributed throughout the TE module, so $\frac{1}{2}$ of the heat goes towards the cold side, and $\frac{1}{2}$ of the heat goes towards the hot side.

\section{Proposed Test Platform for TEG Testing}

The complete block diagram of the proposed test platform for TEG performance degradation evaluation is shown in Figure 2. It is composed of a PC computer, a data acquisition system (DAQ), and the test platform apparatus developed in this work. A LabVIEW ${ }^{\mathrm{TM}}$-based Virtual Instrument (VI) runs independently two PID controllers $\left(P I D_{1}\right.$ and $\left.P I D_{2}\right)$ that control the thermoelectric coolers, $T E C_{1}$ and $T E C_{2}$, in order to maintain their temperatures in the user-defined setpoints. The feedback paths to the controllers are performed by two $K$ type thermocouple $T P_{1}$ and $T P_{2}$ which were chosen for their sensitivity and their operation range. The TEG-under-Test is sandwiched by $T E C_{1}$ and $T E C_{2}$ as well as by heat reservoirs, as shown in Figure 2, in order to create a heat storage that allows a soft changing of temperature. The actuators for both $T E C_{1}$ and $T E C_{2}$ are carried out by two electronic power drives. In both ends of the apparatus, a heat sink is attached to a fan cooler in order to reject the heat flow on the opposite plate of the TECs. In order to reduce the thermal contact resistance, all plates and sides are connected thermally by a thin layer of thermal grease.

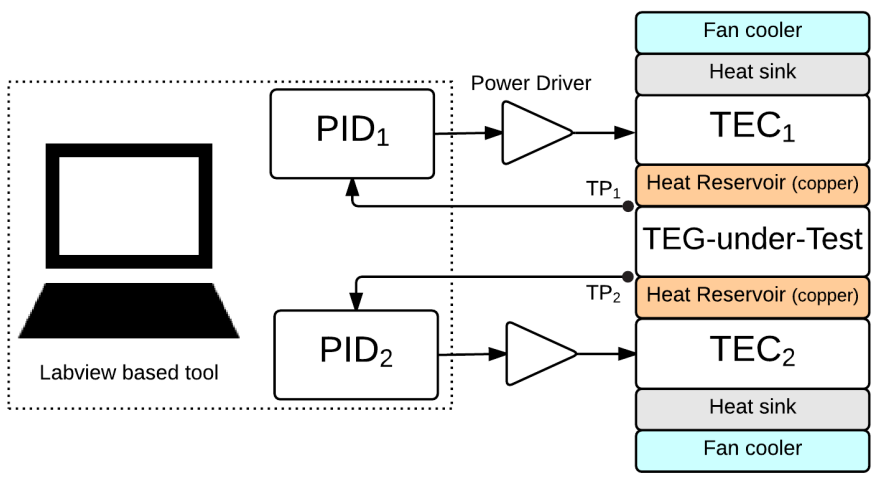

Fig. 2. Block Diagram of the Proposed TEG Test Platform.

As can be seen in Figure 2, from the TEG-Under-Test upward or downward the test platform is symmetrical. In this way, any TEC can generate $T_{H}$ or $T_{C}$ to be applied to the TEG-Under-Test, then the test platform is capable to produce positive $\Delta T>0$, as shown in Figure 3(a), and negative $\Delta T<0$, as shown in Figure 3(b), consequently generating heat flowing up-down and down-up, respectively. Figure 4 shows an ideal thermal cycling that can be obtained by the platform.

\section{A. Thermal cycling Generation}

In order to generate thermal cycling, the designed VI has to be configured properly setting up $T_{H}, T_{C}$, the cycle period $T$ and the number of thermoelectric cycles, as shown in Figure 5. The produced $\Delta T$ is positive in $\frac{1}{2} T$ and $\Delta T$ is negative in the next $\frac{1}{2} T$ as shown in Figure 4. As a result, it is generated thermal cycling periods where the temperatures on both sides are inverted frequently resulting in stress in the thermoelectric material structure. With these applied thermal shocks, it has be possible to degrade the TEG-under-test in a shorter period of time when compared to other platforms as those presented in [9][1][6]. A picture of the experimental TEG test platform is shown in Figure 6.

The TE module used to operate as TEC and TEG was a commercial thermoelectric module made of $B i_{2} T e_{3}$. Specifi- 


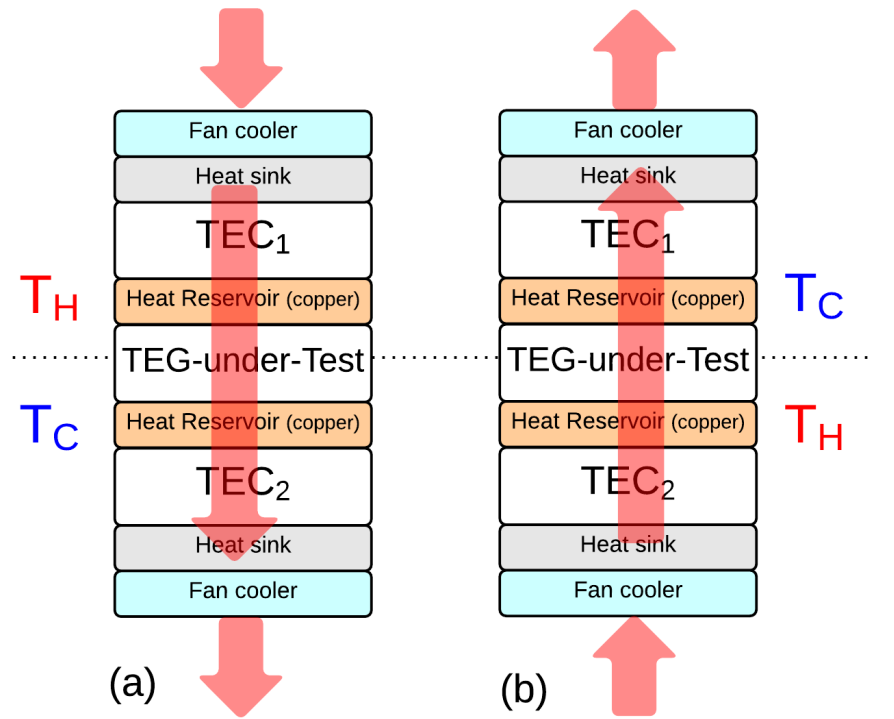

Fig. 3. Symmetrical Operation of the TEG Test Platform.

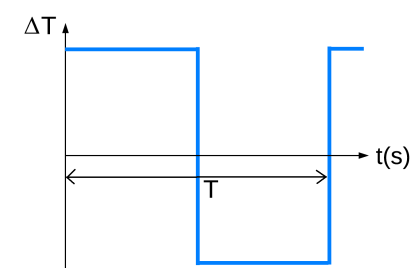

Fig. 4. Ideal Thermal Cycling aimed of the proposed platform.

cally, it was the model TEG1-241-1.0-1.2 from Everredtronics that presents the specifications given in Table I.

TABLE I

Thermoelectric Module SPECIFICATIONS.

\begin{tabular}{cc}
\hline Specification & Value \\
\hline Number of Thermocouples (pn juntions) & 127 \\
\hline Dimensions & $40 \mathrm{~mm} \times 40 \mathrm{~mm} \times 3,3 \mathrm{~mm}$ \\
\hline$T_{\max }$ & $235^{\circ} \mathrm{C}$ \\
\hline$I_{\max }$ & $2.8 \mathrm{~A}$ \\
\hline$R_{i n}$ & $10.1 \Omega$ \\
\hline
\end{tabular}

\section{EXPERIMENTAL RESUlts}

In order to validate the proposed TEG test platform, it was carried out some experiments with a specified thermal cycling curve to evaluate some TEG parameters.

\section{A. Specification of thermal cycling}

In order to realise the experiments, the TECs temperature setpoints were set in $20^{\circ} \mathrm{C}$ and $40^{\circ} \mathrm{C}$. The defined thermal cycling period was 900 seconds ( 15 minutes) meanings that an inversion of TECs temperature setpoints occur in each 450 seconds $(7.5$ minutes $)$. The resulted thermal cycling curve

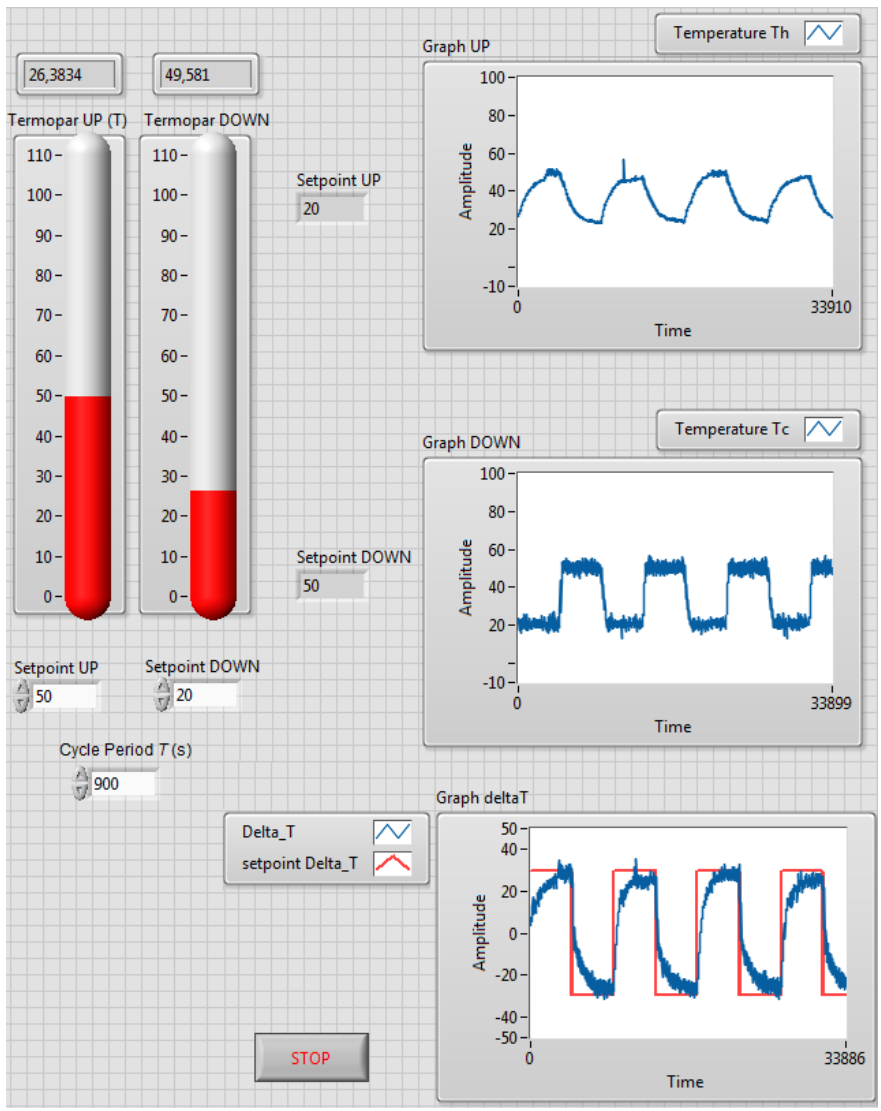

Fig. 5. Virtual Instrument.

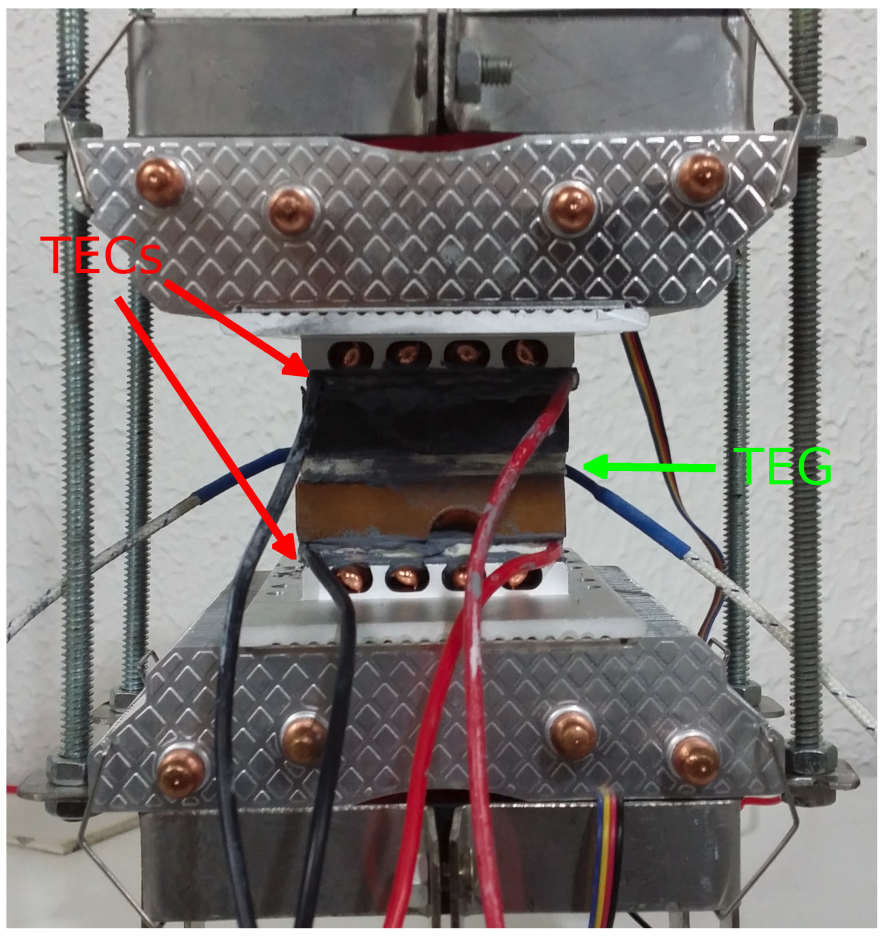

Fig. 6. Experimental TEG test platform. 
is shown in Figure 7 where can be observed the temperatures measured in both sides of TEG-under-Test. The thermal cycling pattern applied on the TEG-under-test is shown in Figure 8 where $\Delta T$ is $+20^{\circ} \mathrm{C}$ and $-20^{\circ} \mathrm{C}$ after each halfcycle.

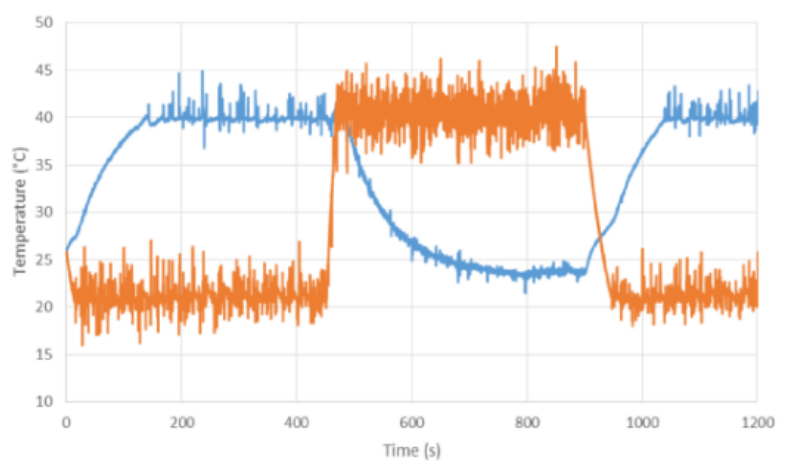

Fig. 7. Measured temperatures in both TEG-under-Test sides.

The chosen specification of the thermal cycling $\Delta T$ was defined based on environmental range which are often applied on thermoelectric-based energy harvesting system.

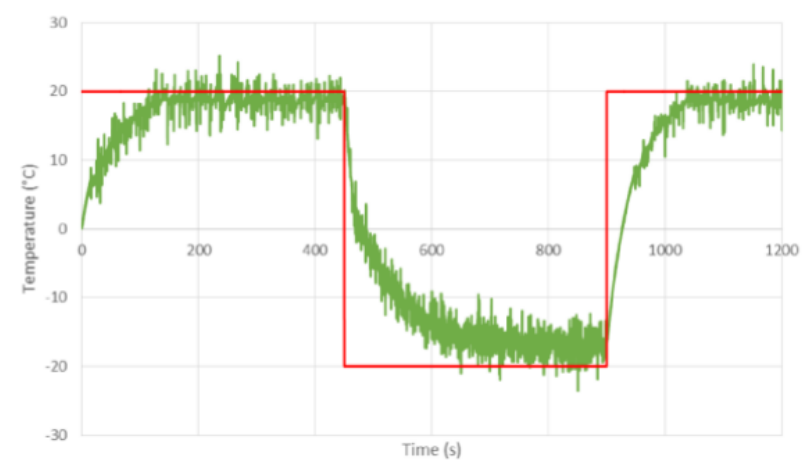

Fig. 8. Thermal Cycling.

\section{B. Measuring and Calculations of thermoelectric parameters}

In order to evaluate the parameters and the figure of merit ZT of the TEG, the Harman's method, proposed by T. C. Harman in 1958, was used. This method was chosen based on studies that compare it to other methods as described in [1] where the Harman's method presented satisfactory results for TEG manufacturers.

The Harman's Method is based on coexistence of two voltages: the Seebeck voltage $\left(V_{S}\right)$ and resistive voltage $\left(V_{R}\right)$. For that, an electric current $I_{T}$ is applied in the TEG-undertest and when the sides of the TEG are on steady state, a total voltage $\left(V_{T}\right)$ is generated by the sum of $V_{S}$ and $V_{R}$ voltages. In practice, to obtain $V_{S}$ and $V_{R}$ voltages the measurements are made as shown in Figure 9.

In Figure 9(a), $I_{T}$ is applied at a period $t=t_{\text {off }}-t_{\text {on }}$ that is the time needed to achieve the maximum value of the total voltage $\left(V_{T}\right)$ and in Figure 9(b) are presented the values of the $V_{T}, V_{S}$ and $V_{R}$. At the instant that $I_{T}$ is applied, only $V_{R}$ is

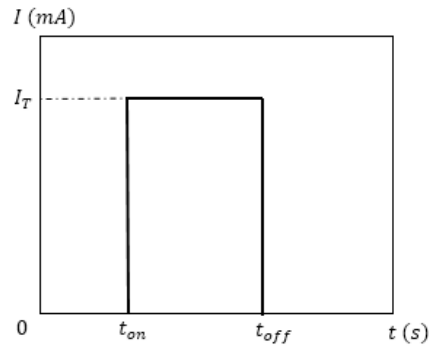

(a)

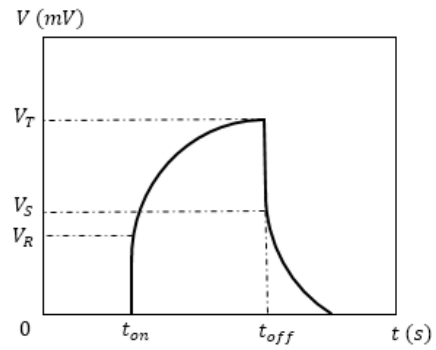

(b)
Fig. 9. Principles of Harman's Method.

presented on the TEG and when the $V$ achieves its maximum value, $V_{R}$ is added to $V_{S}$ to produce $V_{T}$, as a result. When $I_{T}$ is cut off, $V_{R}=0$ and the only voltage produced is $V_{S}$ produced by the last difference of the temperature measured. With the voltages and temperature difference values, these values are applied into the following equations for calculations of the TEG parameters:

$$
\begin{gathered}
R_{\text {in }}=V_{R} / I_{T} \\
\alpha=\frac{V_{S}}{\Delta T} \\
\rho=R_{\text {in }}\left(\frac{A}{L}\right) \\
\lambda=\left(\alpha \frac{I T}{\Delta T}\right)\left(\frac{A}{L}\right)
\end{gathered}
$$

where $R_{\text {in }}$ is the inner resistance, $\alpha$ is the Seebeck coefficient, $\lambda$ is the thermal conductivity, $\rho$ is the electricity conductivity of the TEG-under-measurement.

For the application of Harman's method, $I_{T}=10 \mathrm{~mA}$ and $t=70$ seconds and the current curve was as shown in Figure 10. The measurement process based on Harman's method was performed 30 times for precision considerations. In Figure 11 is presented a voltage signal produced by the TEG that was used by the application of Harman's method.

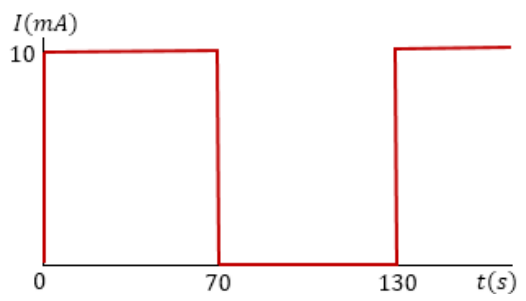

Fig. 10. Current Flow Cycle.

In order to evaluate the TEG-under-Test degradation, it is submitted to Harman's method before the thermal cycling and after a defined number of thermal cycling. The measured average voltages before thermal cycling were $V_{T}=8.39 \mathrm{mV}$, $V_{S}=6.48 \mathrm{mV}, V_{R}=1.90 \mathrm{mV}$ and the average difference of temperature $\Delta T=0.22^{\circ} \mathrm{C}$. 


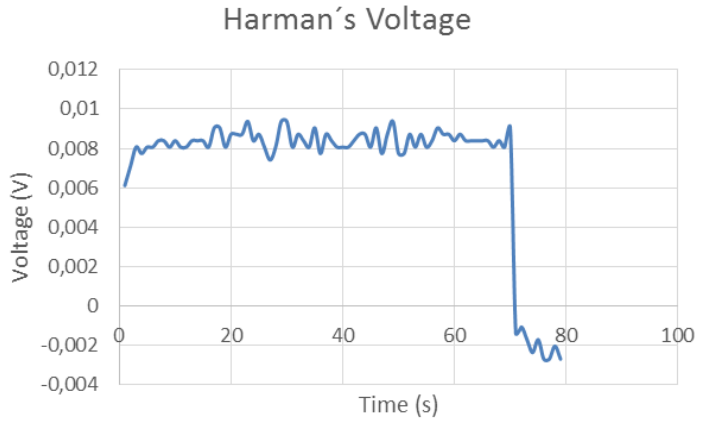

Fig. 11. Voltage Measured on Hardmans Method.

The standard TE performance metric is the non-dimensional figure of merit, $Z T$, which depends on the thermal conductivity $\lambda$, the electrical conductivity $\rho$ and Seebeck coefficient $(\alpha)$, and is given by [1]:

$$
Z \bar{T}=\frac{\rho \alpha^{2}}{\lambda} \bar{T}
$$

where $\bar{T}$ is the average temperature of the module (taken as the mean temperature of the hot and cold plates).

In this way, before thermal cycling, the TEG-under-Test parameters are calculated using Equation 3, 4, 5, 6 and 7 and the results are shown on Table II.

TABLE II

PARAMETERS BEFORE THERMAL CYCLING.

\begin{tabular}{cc}
\hline Inner resistance $\left(R_{i n}\right)$ & $1.69 \Omega$ \\
\hline Seebeck coefficient $(\alpha)$ & $30.8 \mathrm{mV} / \mathrm{K}$ \\
\hline Thermal conductivity $(\lambda)$ & $2.16 \mathrm{K.mm} / \mathrm{mW}$ \\
\hline Electricity conductivity $(\rho)$ & $0.368 \Omega / \mathrm{mm}$ \\
\hline Figure of Merit $(Z T)$ & $89.4 \cdot 10^{-3}$ \\
\hline
\end{tabular}

After 548 thermal cycling (about 137 hours), the TEGunder-test parameters have presented the values shown in Table III because the measured voltages were $V_{T}=7.97 \mathrm{mV}$, $V_{S}=6.21 \mathrm{mV}$ and $V_{R}=1.76 \mathrm{~V}$ and the difference of temperature was $\Delta T=0.21^{\circ} \mathrm{C}$.

TABLE III

PARAMEters After Thermal CyCling.

\begin{tabular}{cc}
\hline Inner resistance $\left(R_{\text {in }}\right)$ & $1.85 \Omega$ \\
\hline Seebeck coefficient $(\alpha)$ & $29.6 \mathrm{mV} / \mathrm{K}$ \\
\hline Thermal conductivity $(\lambda)$ & $1.97 \mathrm{~K} . \mathrm{mm} / \mathrm{mW}$ \\
\hline Electricity conductivity $(\rho)$ & $0.404 \Omega / \mathrm{mm}$ \\
\hline Figure of Merit $(Z T)$ & $72.6 \cdot 10^{-3}$ \\
\hline
\end{tabular}

By comparing the values of Table II and III, it can be seen a variation on TEG-under-test parameters. The inner resistance increase $9.8 \%$, the Seebeck coefficient reduces $3.9 \%$, whereas his variation depends on Seebeck voltage, the thermal conductivity reduced $8.6 \%$ and the electric conductivity decrease
9.6\%. The non-dimensional parameter $Z T$ decreased $18.7 \%$ when compared to its value before thermal cycling.

\section{CONClusion}

In this paper, it was proposed a complete TEG test platform that shows to be capable to apply specified thermal cycling pattern in a thermoelectric generator under test. The proposed platform is composed of a PC computer and the test platform apparatus that is controlled by a $\mathrm{LabVIEW}^{\mathrm{TM}}$-based PID control system. As experimental procedure a TEG-under-test parameters are evaluated before and after thermal cycling by the Harman's Method. Experimental results have shown the applicability and efficiency of the proposed TEG test platform.

\section{ACKNOWLEDGMENT}

This project was financially supported by CAPES-Brazil (Grant Procs. 23038.007101/2011-41 PNPD 2878/2011), and CNPq-Brazil (Grant Procs. 573738/2008-4 INCT NAMITEC).

\section{REFERENCES}

[1] M. Barako, W. Park, A. Marconnet, M. Asheghi, and K. E. Goodson, "A reliability study with infrared imaging of thermoelectric modules under thermal cycling," in Thermal and Thermomechanical Phenomena in Electronic Systems (ITherm), 2012 13th IEEE Intersociety Conference on, May 2012, pp. 86-92.

[2] A. Harb, "Energy harvesting: State-of-the-art," Renewable Energy, vol. 36, no. 10, pp. 2641-2654, 2011. [Online]. Available: http://EconPapers.repec.org/RePEc:eee:renene:v:36:y:2011:i:10:p:26412654

[3] B. I. Ismail and W. H. Ahmed, "Thermoelectric power generation using waste-heat energy as an alternative green technology," Recent Patents on Electrical Engineering, vol. 2, no. 1, pp. 27-39, 2009.

[4] L. xian Ni, K. Sun, H. fei Wu, Z. Chen, and Y. Xing, "A high efficiency step-up dc-dc converter for thermoelectric generator with wide input voltage range," in Industrial Electronics (ISIE), 2012 IEEE International Symposium on, May 2012, pp. 52-57.

[5] C. Bobean and V. Pavel, "The study and modeling of a thermoelectric generator module," in Advanced Topics in Electrical Engineering (ATEE), 2013 8th International Symposium on, May 2013, pp. 1-4.

[6] W. Park, M. Barako, A. Marconnet, M. Asheghi, and K. E. Goodson, "Effect of thermal cycling on commercial thermoelectric modules," in Thermal and Thermomechanical Phenomena in Electronic Systems (ITherm), 2012 13th IEEE Intersociety Conference on, May 2012, pp. 107-112.

[7] Y. K. Tan and S. K. P. (Eds.), Review of Energy Harvesting Technologies for Sustainable WSN, Sustainable Wireless Sensor Networks. United States: InTech, 2010.

[8] S. Priya and D. J. E. Inman, Energy Harvesting Technologies, 1st ed. United States: Springer US, 2009.

[9] E. Hatzikraniotis, K. Zorbas, I. Samaras, T. Kyratsi, and K. Paraskevopoulos, "Efficiency study of a commercial thermoelectric power generator (teg) under thermal cycling," Journal of Electronic Materials, vol. 39, no. 9, pp. 2112-2116, 2010. [Online]. Available: http://dx.doi.org/10.1007/s11664-009-0988-8

[10] Y. K. T. (Ed.), Modeling and Simulation of Thermoelectric Energy Harvesting Processes, Sustainable Energy Harvesting Technologies Past, Present and Future, 1st ed. United States: InTech, 2011.

[11] I. Laird and D. Lu, "Spice steady state modelling of thermoelectric generators involving the thomson effect," in IECON 2011 - 37th Annual Conference on IEEE Industrial Electronics Society, Nov 2011, pp. 1584 1589.

[12] A. Bitschi, "Modelling of thermoelectric devices for electric power generation,” Ph.D. dissertation, Diss., Eidgenssische Technische Hochschule ETH Zrich, Zrich, 2009, 18441. 